\title{
REFLEXÕES SOBRE A FORMAÇÃO DO ACERVO DA ACADEMIA DE DIREITO DO LARGO DE SÃO FRANCISCO: DO SÉCULO XIX AOS NOSSOS DIAS
}

\author{
REFLECTIONS ON THE FORMATION OF THE LAW LIBRARY OF THE LARGO DE SÃO FRANCISCO
}

LAW SCHOOL: FROM THE $19^{\text {th }}$ CENTURY TO THE PRESENT DAY

\author{
Maíra Cunha de Souza Maria \\ Maria Lucia Beffa \\ Sérgio Carlos Novaes \\ Sílvia Mara de Andrade Jastwebski*
}

\begin{abstract}
Resumo:
O trabalho apresenta algumas reflexões sobre a história da formação do acervo acadêmico dos cursos jurídicos do Brasil criados no século XIX, especificamente da Faculdade de Direito da Universidade de São Paulo. A primeira Biblioteca Pública de São Paulo, fundada em 1825, exerceu forte influência para que o Convento dos frades franciscanos recebesse a escola de direito criada por Decreto Imperial, em razão de seu fundo bibliográfico de 5.000 mil livros, preponderantemente de cunho eclesiástico, e considerável para os padrões culturais do Brasil à época. Atualmente configura-se como uma importante biblioteca jurídica acadêmica da América Latina e, ao longo da sua história tem sido uma instituição de depósito moral, isto é, recebe doações das mais diversas localidades do país, encaminhadas espontaneamente pelos autores para ter sua obra disponibilizada no acervo do primeiro e um dos mais tradicionais cursos de Direito do Brasil. Atualmente, este acervo está estimado em aproximadamente 400 mil itens, com doações de personalidades brasileiras. Outro ponto estudado refere-se ao estabelecimento de critérios para seleção de material corpo editorial, autores de renome, relevância nos temas abordados etc. - em razão do boom editorial ocorrido na década de 1990, concomitante com o aumento de escolas de Direito no país. Chama-se à reflexão de quem atua na seara jurídica para atentar a pontos relevantes no momento da seleção para não incorrer no erro de avaliar com preconceito, modernidade, ideológico, interesse de estudo pessoal ou embasado apenas na data de publicação da obra. As ciências humanas, diferentemente de outras áreas, têm sua obsolescência mais lenta ou inexistente, decorrendo em grave erro para o Direito julgar exclusivamente pela data de publicação, o que torna premente aos profissionais bibliotecários dominarem conceitos básicos na área de atuação para que as bibliotecas sejam depositárias de material bibliográfico de qualidade.

Palavras-chave: Biblioteca da Faculdade de Direito (São Paulo, Brasil). História da coleção. Aquisição. Seleção.
\end{abstract}

\begin{abstract}
:
The paper presents some reflections about the history of formation of Brazilian law schools libraries in the 19th Century, in special, those of the University of São Paulo Law School library. The first Sao Paulo Public Library, founded in 1825, was
\end{abstract}

Bibliotecários do Serviço de Biblioteca da Faculdade de Direito da USP 
important in the decision to transform the Convent of the Franciscan friars into a Law School, created by an Imperial Decree, because of its bibliographic fund of 5.000 books, mostly about ecclesiastical subjects, was considered very proeminent for Brazilian cultural patterns at the time. This has been qualified as an important academic law library in Latin America and has been a "moral depository" throughout its history, because it has received donations of authors from various locations around the country, which aimed their works available in this library. Currently, this fund is estimated at approximately 400.000 items, included donations made by public personalities. Another subject is about the establishment of criteria for selection of material - editorial board, authors, relevance of the subjects etc. - caused by the editorial boom occurred in the 1990s, concomitant with the increase of law schools in the country. It was called the reflection of who acts in legal research to focus on the relevant points in the selection of works, in order to avoid mistakes in their evaluation. Humanities books, unlike other areas, have a slow or nonexistent obsolescence, so it is a mistake to consider solely by publication date, which makes librarians to master basic concepts in the area of operation for the libraries to be depository of a qualified bibliographic material.

Keywords: College of Law Library (Sao Paulo, Brazil). History of collection. Acquisition. Selection.

\section{Introdução}

O Serviço de Biblioteca e Documentação da Faculdade de Direito da USP, SBD/FDUSP tem uma história de 188 anos de serviços prestados à sua comunidade interna e ao Brasil. Patrimônio cultural da sociedade brasileira, a biblioteca jurídica acadêmica tem sua origem ligada à primeira biblioteca pública da cidade de São Paulo no século XIX, que funcionava nas dependências do Convento de São Francisco. Em 1827, com a criação dos cursos jurídicos no Brasil, a biblioteca foi incorporada à recém-criada Academia de Direito, com um acervo de aproximadamente cinco mil volumes. 


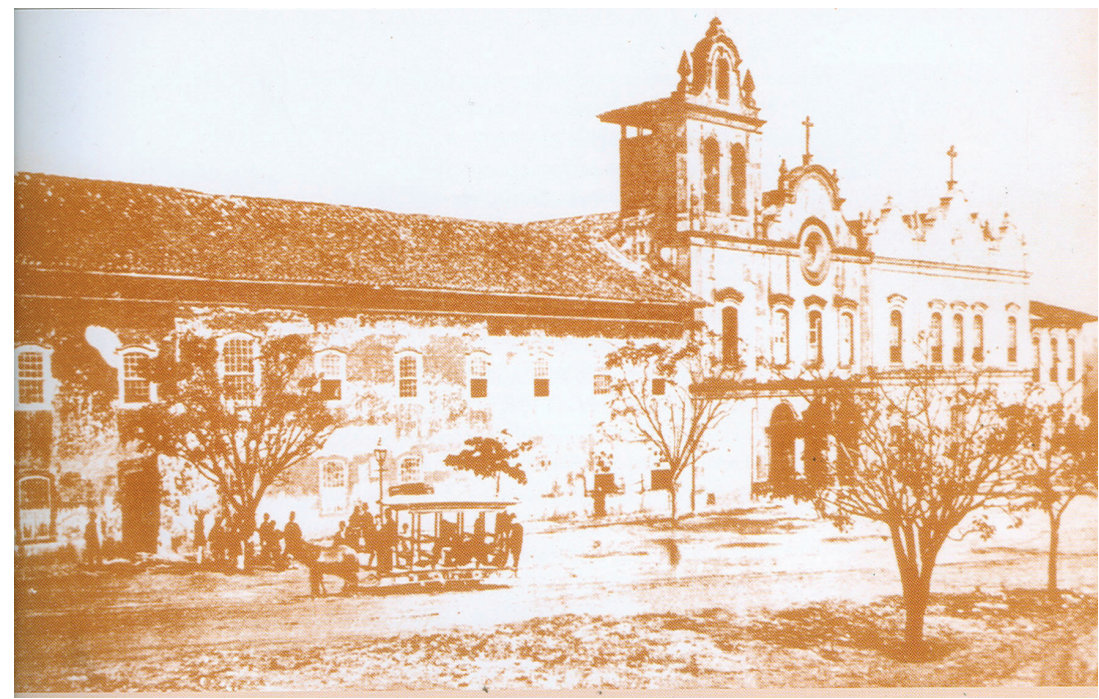

Academia de Direito. Foto de Militão Augusto de Azevedo, c. 1872.

A partir desse contexto pretende-se delinear a formação e a estrutura de seu acervo e apresentar informações que abrangem não apenas a história jurídica do Estado de São Paulo, mas também engloba parte da história do Brasil.

Destaca-se o importante papel desempenhado pelos seus bibliotecários, que desde os primórdios atuam de forma criteriosa e responsável para o desenvolvimento da coleção por sua relevância, para atender as necessidades institucionais de ensino, pesquisa e extensão universitária.

A formação da coleção de uma biblioteca é um imperioso exercício profissional e, conforme afirma Cabral (2005, p. 17) é

[...] a missão mais nobre que nos cabe como profissionais. Pela colecção em si, pela contribuição que resulta para o enriquecimento do patrimônio, pelos serviços que potencia, pela prossecução de um trabalho norteado por parâmetros de preservação e conservação.

Como de conhecimento, fazem parte da aquisição e do desenvolvimento da coleção de uma biblioteca as modalidades doação, compra e permuta. Entretanto, no presente trabalho serão abordadas algumas práticas adotadas ao longo do tempo para o desenvolvimento da coleção, com ênfase para alguns segmentos do acervo recebidos em doação, por trazer no seu âmago maior demanda no âmbito da biblioteca e por sua importância histórica. 
Neste aspecto, para o desenvolvimento da coleção é preciso ter claro qual a missão da instituição, não apenas pelo que está posto no papel, mas de fato executá-la por meio do trabalho no cotidiano.

\section{A origem da Biblioteca e a formação do acervo}

A origem da atual Biblioteca remonta à fundação da primeira Bibliotheca Pública Official de S. Paulo, em Janeiro de 1825.

Quando, em 1827, por meio da Lei de 11 de Agosto, foi aprovada a criação de dois cursos jurídicos no Brasil, a cidade de São Paulo foi uma das escolhidas e a cidade de Olinda foi a outra. O Convento de São Francisco em São Paulo foi eleito para sediar o curso justamente por possuir uma Biblioteca funcionando e com um bibliotecário. Portanto, não fosse a Biblioteca, pode-se deduzir que São Paulo poderia não abrigar um dos cursos jurídicos naquela época.

Ao largo de sua história, a Biblioteca é vista como uma instituição de depósito moral, pois recebe doações das mais diversas localidades do país, encaminhadas pelo desejo espontâneo do autor em ter sua obra constando no acervo da primeira Biblioteca Pública e também do primeiro curso de Direito, daí a relevância de tratar das doações.

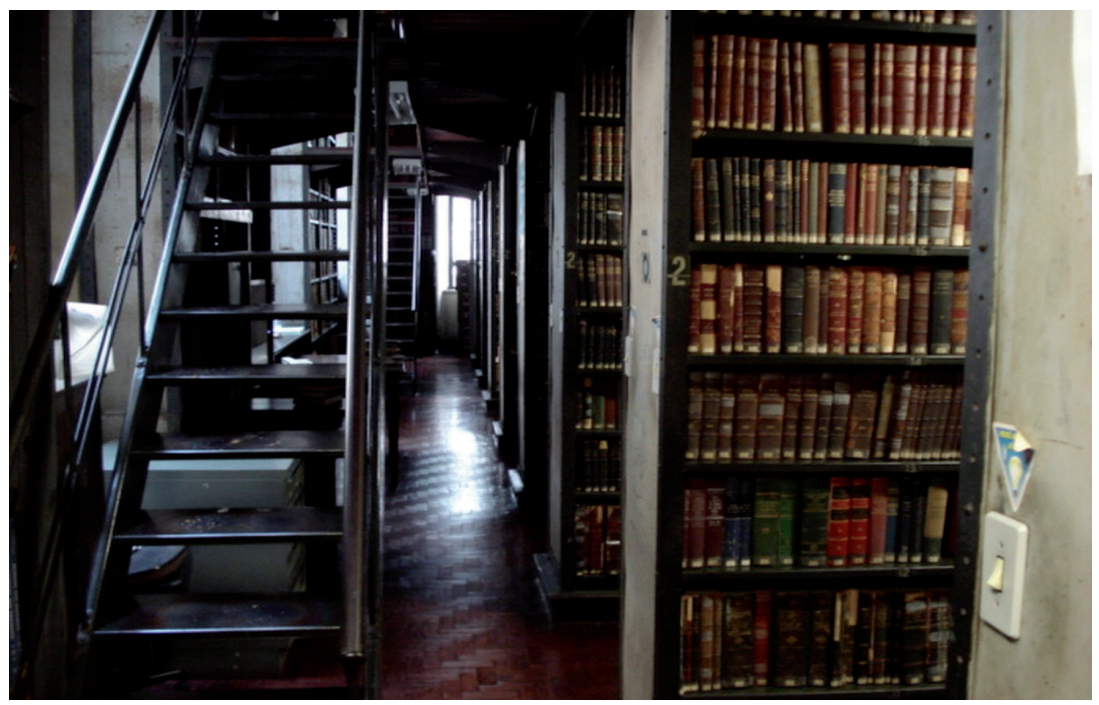

Vista da Biblioteca Central da Faculdade de Direito, 2007. 
Para Vergueiro (1990, p. 3) as bibliotecas do Brasil "tiveram um papel de repositório das manifestações literárias, sendo consideradas como o suprassumo da civilização letrada". Tal afirmação pode ser constatada na Biblioteca da Faculdade de Direito, visto seu eclético acervo.

Há inúmeros assuntos não diretamente relacionados ao mundo jurídico acadêmico, tal como aqueles de cunho eclesiástico, em razão do legado franciscano. Algumas obras são difíceis de encontrar como "Huma nota sobre o quebra kylos da Parayba do Norte", de 1875, não encontrada na Biblioteca Nacional, ou a obra de Antonil, "Cultura e opulência do Brasil por suas drogas e minas" [...], de 1711, com três exemplares conhecidos no Brasil, entre outras.

No livro manuscrito usado para a administração da Biblioteca da Academia de 1857 a 1900, pode ser encontrada um relato do bel. Fernando Mendes de Almeida, bibliotecário, encaminhada ao diretor o Conselheiro Vicente Pires da Mota, no dia 18 de Julho de 1878, dando ciência da doação recebida de 1.056 volumes, sendo a maior parte de direito, da família do aluno quartanista Joaquim Vidal Leite Ribeiro Júnior e afirma que "ser mui valioso este donativo, preencheram algumas de suas obras certas lacunas que existiam nesta biblioteca". Na mensagem discorre um pouco sobre o estado das obras dizendo que a maioria está encadernada e em muito bom estado.

Neste documento histórico, em 20 de dezembro de 1881, informou ao diretor sobre o número de obras adquiridas no ano, no período de 7 de janeiro a 20 de dezembro, um total de 249 obras em 504 volumes, com a ressalva de que parte das obras relacionadas foi ofertada à biblioteca pelos próprios autores mediante pedido do bibliotecário responsável pela biblioteca da Faculdade.

Esta Biblioteca tem uma função social a cumprir, pois além de atender às necessidades endógenas, em razão de sua vocação histórica e respeitando o propósito pelo qual foi criada, deve atender também à sociedade em razão do seu estoque de informação. Pela importância de seu acervo é considerado um patrimônio cultural, referência para o Brasil e quem sabe para o mundo.

Como abordado por Miranda (2007, p. 2),

[...] a informação tornou-se a mais poderosa força de transformação do homem, encontrando-se presente no cotidiano do individuo através das relações sociais, econômicas, e, culturais e adquirindo, neste sentido, um caráter decisivo para o alcance da cidadania, das metas e dos objetivos propostos pelo próprio homem, que cria um vinculo de dependência com a informação para melhor adaptação ao meio em que vivem.

Os usuários, em especial alunos e docentes, como um mantra, argumentam que o acervo é desatualizado e por isso suas pesquisas são insatisfatórias. Respeitada uma 
fração de verdade na afirmação, é necessário racionalmente entender que biblioteca alguma será totalmente completa, premissa que Carrión Gútiez (1990, p. 64-65) afirma “debido al precio de los productos, al aumento de la producción, a las necesidades crecientes de los usuários". Concluindo, as coleções geralmente são incompletas.

Ao longo de sua história, importantes doações foram recebidas de docentes e outras personalidades, como as de Arouche Rendon, Pires da Mota, Macedo Soares, Pedro Lessa, Tulio Ascarelli, Waldemar Ferreira, Fernando Pereira Sodero, entre outras. São obras italianas, francesas, inglesas das mais diversas datas de publicação que o numerário da Biblioteca não conseguiria abarcar, criando inevitavelmente um hiato para pesquisa.

Além das doações recebidas espontaneamente, não se pode deixar de mencionar o empenho dos bibliotecários, que estabeleceram uma profícua permuta com as mais diversas instituições nacionais e estrangeiras. Nos protocolos das correspondências expedidas pela Biblioteca há nomes de personalidades da cultura, juristas e políticos da vida nacional. Entre muitos aparecem Afrânio Peixoto, Alceu de Amoroso Lima, Luiz Aranha Pereira, Menotti Del Picchia, Nereu Ramos, Clóvis Bevilaqua e Getúlio Vargas. Há ainda registros de expedição para universidades da América Latina, tais como a Universidad de La Republica do Chile, Universidad de la Republica Oriental del Uruguay.

No relatório da Faculdade de 1934, há uma extensa relação de pessoas e instituições que doaram revistas ou livros no período de 1933 a 1934, entre elas a Editora Nacional, Ecole Libre de Sciences Politiques, Universidade de Montpelier, Universidade de Oviedo, Gofredo da Silva Telles, entre outros. Essa dinâmica toda pode ser avigorada com uma visita à Biblioteca para conhecer este fundo bibliográfico de grande valor para a cultura em geral e, particularmente, para a ciência jurídica brasileira. Além de ser um bom diletantismo para aqueles que se lançam a pesquisar e estudar.

O esforço profissional em torno de superar limites pode ser considerado como papel de educador do profissional da informação, bem como seu compromisso ético como mediador entre o conhecimento e o pesquisador.

A ciência do Direito como uma ciência humana transcende datas e povos, portanto, dizer que uma obra é velha ou superada é desconhecer os institutos que a regem, motivo pelo qual para selecionar, avaliar, desbastar uma coleção precisa-se mais que algumas regras pré-estabelecidas, é importante ser conhecedor da área de atuação.

Nas humanidades a monografia tem grande valia, ao contrário de outras áreas, que preferem os periódicos. Neste sentido, afirma Orera Orera (2002, p. 96) que "en el campo de las ciencias sociales y humanísticas se consideran de mayor interés las monografías," cuja obsolescencia é mais lenta. Edilenice Passos (1994, p. 364) também faz menção à vida longeva da doutrina jurídica quando escreve que a "informação jurídica difere de alguns tipos de informação, em um aspecto muito importante: a longevidade."

No mesmo sentido Wolthers (1985, p. 13) afirma que a ciência jurídica, 
[...] ao contrário de outras ciências, em que as informações se tornam ultrapassadas e obsoletas, quando substituídas por outras mais atuais, o texto jurídico é eterno a nível de consulta, de referência e de precedente e também a nível de aplicação a fatos e situações ocorridas em épocas regidas por institutos legais distintos. Logo, nada pode ser destruído e o armazenamento é constante, contínuo e permanente.

López-Muñiz Goñi (1984 apud PASSOS, 1994, p. 364) também aponta a longevidade da doutrina jurídica ao afirmar que:

[...] a informação jurídica tem uma validade quase permanente, interessando ao jurista não apenas a última que foi publicada, a que foi legislada, mas também a anterior, ainda que a revogação de uma norma legal deixe sem efeito essas disposições, seus preceitos serão aplicáveis àqueles atos jurídicos que tenham nascido sob a sua vigência, e portanto a eficácia perdura além da própria revogação. Daí que não se pode prescindir de documentos jurídicos sob o pretexto da antiguidade.

Ressalta-se que algumas doações são inócuas, pelo fato do porte da instituição receptora, embora uma obra recebida possa valer por outras desnecessárias. Para ilustrar, uma obra relevante do Brasil Império pode não ter preço, ou quiçá ter um valor impagável pela Biblioteca, sempre com recursos restritos. Tal obra pode ajudar a compor a coleção e otimizar recursos para itens difíceis de serem adquiridos por compra.

Nesse sentido, a oferta da família de Brasílio Machado foi muito adequada, pois apesar dos livros de literatura e religião, foi identificado um jornal do século XIX, o Diabo Coxo, marco do início da charge política no Brasil. Também foi localizado um manuscrito português que está atribuído a D. Luis da Cunha, que governou Portugal no século XVII. Este documento exige estudos para comprovar autoria e determinar o período histórico.



Diabo Coxo, com ilustrações de Angelo Agostini

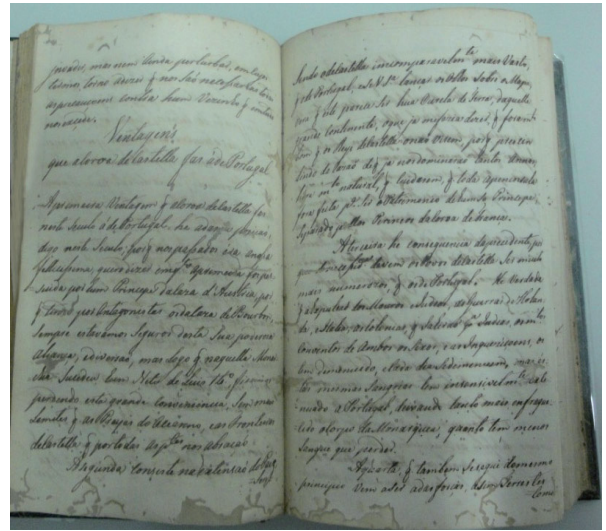

Manuscrito português do século 17 
Outras obras oitocentistas foram encontradas e, mediante pesquisas em bibliotecas brasileiras e estrangeiras não resultaram em resposta positiva. Nas doações apontadas, pôde-se averiguar que muitos livros representavam lacunas difíceis de serem suplantadas tais como obras relevantes e há muito publicadas, edições esgotadas, com ex-dono ou com dedicatórias de personalidades. Portanto, como comumente a verba é limitada, não é possível pensar em aquisição pela compra retrospectiva em função da demanda reprimida sempre existente.

Neste sentido, Sousa (2010, [p. 7]), alerta que doações são aceitas pelo objetivo de tentar preencher eventuais falhas na coleção. Vergueiro (2010, p. 75) entende como "uma inestimável fonte para a aquisição de recursos informacionais: não podem ser absolutamente desprezadas ou encaradas de maneira superficial."

Orera Orera (2002, p. 105), compartilha entendimento similar, pois escreve que a doação "pude resultar muy beneficiosa por el ahorro que supone para la biblioteca y porque pude ser uma via para disponer de documentos que no se comercializan."

Considera que a doação de um acervo é a possibilidade de completar um determinado assunto, pois reflete em si a trajetória da pesquisa, da evolução e da seleção de um aspecto do conhecimento por alguma personalidade.

Outro fator causador de impacto são as doações de bibliotecas de antigos professores que também requerem critérios para a seleção do material e verificação da pertinência e relevância de cada obra à demanda existente.

Entretanto, algumas especificidades devem ser observadas, como por exemplo possuir um exemplar no acervo, um autor consagrado, uma obra antiga e valiosa ou de período que mereça redobrar cautela. Recomenda-se verificar o estado físico do livro patrimoniado para se ter elementos suficientes para a tomada de decisão de substituição da obra existente ou de repasse à instituições congêneres.

A Biblioteca, em sua história, manteve relacionamento com editoras para receber doações de seus lançamentos, entretanto, estas tinham a liberdade para doar títulos em quantidade que lhes aprouvessem, sem consulta prévia. Muitas editoras, particularmente as nacionais e mais ainda as editoras que surgiram no mercado com o advento dos inúmeros cursos jurídicos criados na década de 1990 no Brasil, encaminham doações de títulos dos respectivos catálogos em exemplares. Neste diapasão, porém nem tudo que é doado pode ou deve ser incorporado, pois depende da avaliação.

No Brasil, há milhares de cursos jurídicos e acredita-se que a isto está pari passu associado ao surgimento de novas editoras e à explosão de manuais no mercado livreiro. Constata-se que há edições bem cuidadas e títulos inéditos de autores consagrados, mas comumente a maioria é pouca conhecida da esfera acadêmica.

Diante da multiplicidade de editoras, verifica-se que uma porcentagem das publicações doadas não representa qualidade, por serem livros cuja legislação sofreu 
alteração já contemplada na coleção, livros esquecidos nos estoques das livrarias e temas não pertinentes ao acervo. Decorrendo daí a importância dos critérios para a inclusão das obras no acervo, com a participação na seleção do corpo docente, especialmente.

As editoras já consolidadas no mercado jurídico também participam dessas doações, mas geralmente com menor número de exemplares dos seus catálogos. Estas editoras tradicionais e especializadas na área têm em seus portfólios autores consagrados do mundo jurídico, mas não significa que não deve haver análise das publicações, apenas que há um indício de respeitabilidade ou de fumus boni iuris, com a qualidade e atualidade para pesquisa científica.

Escreve Miranda (2003, p. 1-2) que do bibliotecário requer "uma atuação diferenciada em razão do descontrole provocado pela 'poluição de informação', exigindo da biblioteca uma análise apurada para "garantir a disponibilidade de obras confiáveis nos diversos suportes informacionais."

Corrobora Vergueiro (1990, p. 29) com a preocupação, afirmando que: "boa parte da produção colocada no mercado por esta explosão é constituída, na realidade, de material de pouca importância." Pressupõe-se, portanto, que no Direito não é diferente.

Para Miranda (2003, p. 4) o crescimento da demanda de informação jurídica, se dá pela constante alteração na legislação, que no Brasil é muito grande. Entretanto, a esta leitura faz-se uma ponderação, acrescentando à sua proposição que o mercado livreiro jurídico emergiu em especial na década de 1990, quando novos cursos de Direito se multiplicaram pelo país.

Outro ponto importante, a médio e longo prazo, e salutar para a Biblioteca, é a observância da qualidade do papel empregado na edição, se de má qualidade a vida útil da obra está fadada a ser mais efêmera. Portanto, do ponto de vista editorial, este item deveria ser considerado quando de uma edição criteriosa com a preservação e longevidade do suporte.

Todas estas situações precisam ser analisadas friamente para não incorrer em erro e consequentemente em prejuízo ao seu público, mas certamente consumirá um tempo para efetuar segura avaliação. A formação do acervo requer um profissional familiarizado com o assunto, com a história da coleção envolvida e com a história da instituição no cenário da sociedade.

Para Vergueiro (2010, p. 5) o bibliotecário no processo de seleção "interfere na vida de inúmeras pessoas", ao qual se acrescenta um agravante, isto é, se não houver envolvimento e, ainda mais, conhecimento da área em que atua, a interferência pode ser maior e mais negativa. Para ele, queira ou não, o bibliotecário está "permanentemente interferindo no processo social".

Vergueiro (2010, p. 7) levantou o problema dizendo que: 
[...] nem todos os profissionais conhecem suficientemente bem o acervo sob sua responsabilidade, de modo a poderem tomar decisões eficientes a respeito de inclusões ou exclusões que poderiam ou deveriam ser feitas nesse acervo.

Sem parafrasear, cita-se Cabral, (2005, p.12) ipsis litteris:

Um conhecimento profundo das coleções não se adquire nem por magia nem mecanicamente. A receita tambem não consta dos manuais, logo, o desenvolvimento e enriquecimento das coleções não acontece by the book. Aprende-se a conhecer as coleções convivendo com elas; aprende-se a conhecer os autores, os livros, as temáticas, lidando diariamente com eles. Certamente que o gosto pessoal conta, mas como o ouvido para a musica, também se educa. Isto é importante ter presente porque se trata de uma aprendizagem que demora anos a cimentar. E conhecer as colecções tem uma tripla finalidade; por um lado, para mais fundamentadamente se processarem novas posições; por outro lado, para antecipar serviços de qualidade superior e, finalmente, para melhor se concretizar o exercicio de acções de preservação e conservação.

Neste sentido Orera Orera (2002, p. 95) diz que "el bibliotecario debe ser un buen conocedor de los distintos documentos para elegir los más adecuados de acuerdo con las necesidades de información de los usuarios."

Ao usuário, afirma Vergueiro (1989, p. 55), deve ser garantido o amplo acesso sem restrição, observando a pertinência e a relevância da obra, o perfil da instituição e de sua biblioteca, depreendendo que o bibliotecário não é censor ou não pode e não deve ser censor na formação da coleção. Pautado nos princípios fundamentais do filósofo hindu Ranganatham "uma biblioteca é um organismo em crescimento", verdade indiscutível.

Focando nas particularidades da seara jurídica, além de questões ideológicas, filosóficas, entre outras, o direito é reflexo da vida em sociedade desde sempre. Então, outro ponto que não pode ser ignorado é a transversalidade e transcendentalidade temporal dos seus institutos.

As ciências humanas diferentemente das áreas biológicas e exatas têm sua obsolescência muito mais lenta ou mesmo não existe. Decorre que ignorar o valor de uma obra julgando pela data de publicação é incorrer em um grave erro para a ciência do Direito.

Miranda (2003, p. 9) entende que uma biblioteca jurídica acadêmica precisa ter como princípio basilar o estudo das "necessidades da instituição mantenedora e o usuário individual inserido dentro de uma cultura organizacional, com necessidades diversificadas e demandas a serem suprimidas." 
A permuta, outro tipo de aquisição, é o resultado da troca de produções com outras instituições congêneres, nacionais ou estrangeiras, motivada na busca de ampliar as possibilidades de bibliografia para o desenvolvimento da pesquisa. Porém esta modalidade não é a mais impactante na demanda de formação do acervo da Biblioteca em estudo.

Para permutar um periódico, aconselha-se verificar a instituição que o publica, o corpo editorial, os autores, a periodicidade e o tempo de existência. Este ponto é importante, pois a partir dos anos 1990 muitas escolas de direito passaram a editar a revista da instituição, frequentemente para atender exigência dos critérios de avaliação a que são subordinados, sem na verdade contar com uma infraestrutura intelectual e material para dar continuidade ao periódico e nestes casos acaba fadado ao fracasso.

Já no âmbito da aquisição por compra, há apoio de fundação pública que destina quantia para compra de livros, principalmente importados, pois este tipo de agência de fomento no Brasil pode fazer importação direta. As obras nacionais e as que estão disponíveis no mercado nacional são habitualmente adquiridas com verba da própria Universidade.

A modalidade compra representa principalmente as sugestões dos docentes e, em menor grau, as solicitações do corpo discente de graduação e pós-graduação. Alguns docentes trabalham suas listas em conjunto com orientandos, uma vez que os interesses se convergem. Este trabalho conjunto resulta em novas possibilidades de ampliação da pesquisa e do ensino, com a participação de mais membros da comunidade acadêmica.

Não há maior discussão sobre a lista de compra, uma vez que os títulos são referendados pelo corpo docente, faz parte da bibliografia básica do curso, da linha de pesquisa do docente, de obras clássicas importantes para o embasamento do ensino ou novas tendências na seara jurídica. Ao bibliotecário cabe adequar a lista bibliográfica aos recursos disponíveis, o número de exemplares, fazer a conferência se a obra existe no acervo, seu estado de conservação.

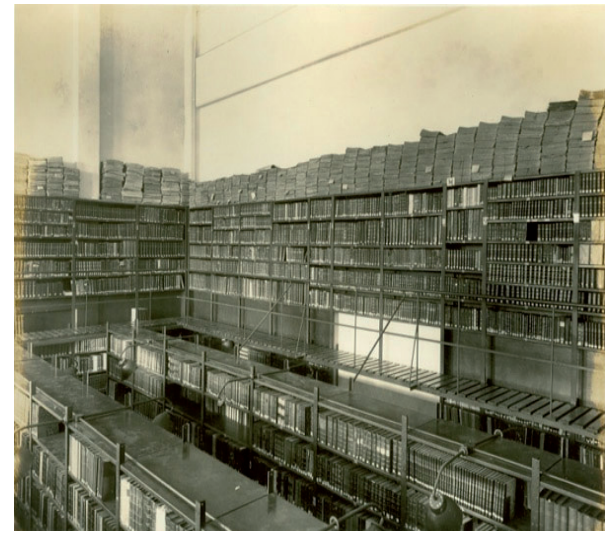

Desenvolvimento do acervo, década de 1930.

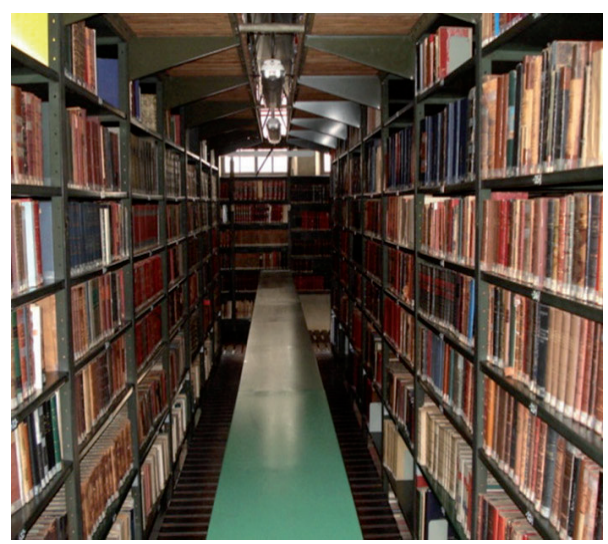

Vista parcial da coleção, 2007. 
3. Avaliando a coleção para desbaste

Apoiando-se em entendimento do professor Vergueiro (1990, p. 104) o desbastamento da coleção compreende três atividades: o descarte, o remanejamento e a conservação.

A justificativa para deixar um acervo dormente no direito se dá ao fato de um assunto não contemplado numa legislação em outro dado momento pode receber acolhida legal, doutrinária ou jurisprudencial.

As obras com poucas demandas de consulta devem ser separadas para observação por um lapso de tempo, isto é, não descartar abruptamente sem haver um período de transição.

Quando o descarte for aplicado não se pode incorrer no erro de repelir uma obra em razão do seu estado físico não ser o ideal. Muita precaução deve ser tomada para não desfazer de modo aleatório com a convicção de que se trata de material obsoleto, ou por censura e ainda por animosidade intelectual.

\section{Conclusão}

A coleção jurídica não deve ser avaliada com conceito de moderno, ideológico, de interesse de estudo pessoal ou embasado na data de publicação.

A partir da análise dos autores citados conclui-se que o conhecimento tácito do bibliotecário é importante para não cometer falhas na avaliação, as quais reverterão na formação do acervo. Neste contexto, destaca-se o quão importante é o bibliotecário possuir conhecimentos da área de atuação.

As doações são essenciais dentro de uma instituição, pois promovem a atualização, enriquecimento e completeza do acervo. É possível receber obras esgotadas, raras e especiais, em melhor estado de conservação do que a já existente e mesmo para aumentar o número de exemplares para melhor atender a demanda de consulta e empréstimo.

Em casos especiais pode-se criar uma reserva técnica com obras significativas para o acervo, entretanto necessitam de triagem com pesquisa nos bancos de dados para estabelecer o destino.

O material bibliográfico requer análise antes de sua incorporação ao acervo, bem como a participação de outras instâncias da Faculdade para tomada de decisão, tais como a Diretoria, o Conselho Técnico Administrativo, a Comissão de Biblioteca.

Enfim, com participação, critério e conhecimento, as doações são bemvindas!

São Paulo, julho de 2013. 


\section{Referências}

ANDRADE, Diva Carraro de; VERGUEIRO, Waldomiro. Aquisição de materiais de informação. Brasília: Briquet de Lemos, 1996.

BEFFA, Maria Lucia; NAPOLEONE, Luciana Maria. Da primeira biblioteca pública oficial de São Paulo à biblioteca da Faculdade de Direito da USP: história da biblioteca de suas origens até a criação da USP. In: BITTAR, Eduardo Bianca. (Coord.). Historia do Direito brasileiro. 2. ed. São Paulo: Atlas, 2003. p. 171-186.

CABRAL, Maria Luisa. Conservação preventiva, porquê? Páginas A\&b, n. 15, p. 7-27, 2005.

CARRIÓN GUTIEZ, Manuel. Manual de bibliotecas. 2 reimpr. Salamanca: Fundación German Sánchez Ruíperez, 1990.

A CONTRIBUIÇÃO da Biblioteca para o catálogo das obras dos antigos alunos. Revista da Faculdade de Direito de São Paulo, São Paulo, v. 30, fasc. 2, p. 331, abr./jun. 1934.

LÓPEZ-MUÑIZ GOÑI, Miguel. Informática jurídica documental. Madrid: Díaz de Santos, 1984. MIRANDA, Ana Cláudia Carvalho de. Desenvolvimento de coleções em bibliotecas universitárias. Revista Digital de Biblioteconomia e Ciência da Informação, Campinas, v. 4, n. 2, p. 1-19, jan./ jun. 2007.

MIRANDA, Ana Cláudia Carvalho de. A qualidade enquanto instrumento na política de desenvolvimento de coleções jurídicas. In: SIMPÓSIO INTERNACIONAL DE PROPRIEDADE INTELECTUAL, INFORMAÇÃO E ÉTICA, 2., 2003, Florianópolis. Anais... Florianópolis: [s.n.], 2003. p. 1-2.

OLIVEIRA, José Alcântara Machado de. Relatório: referente ao ano de 1932. Revista da Faculdade de Direito de São Paulo, São Paulo, v. 39, p. 419-432, 1933.

ORERA ORERA, Luisa. La coleccón: formación, desarrollo y mantenimiento. In: ORERA ORERA, Luisa (Ed.). Manual de biblioteconomia. Madrid: Síntesis, 2002. p. 92-111.

PASSOS, Edilenice Jovelina Lima. O controle da informação jurídica no Brasil: a contribuição do Senado Federal. Ciência da Informação, Brasília, v. 23, n. 3, p. 363-368, set./dez. 1994.

SCHWARCZ, Lilia Moritz. Diabo Coxo. Observatório da Imprensa, São Paulo,n. 323, abr. 2005. Disponível em: <http://www.observatoriodaimprensa.com.br/news/view/lilia_moritz_schwarcz>. Acesso em: 20 maio 2013.

SOUSA, Margarida Maria de. A difícil missão de seleção quando o espaço físico não suporta o crescimento do acervo: a experiência do Serviço de Biblioteca e Documentação da FEA/USP. In: SEMINÁRIO NACIONAL DE BIBLIOTECAS UNIVERSITÁRIAS, 16., 2010, Rio de Janeiro, Anais eletrônicos... Rio de Janeiro: UFRJ/SIBi, 2010. Disponível em: <http://www.gapcongressos. com.br/eventos/z0070/trabalhos/final_198.pdf>. Acesso em: 20 maio 2013. 
VERGUEIRO, Waldomiro de Castro Santos. Bibliotecas públicas e mudança social: a contribuição do desenvolvimento de coleções. 1990. 242 f. Tese (Doutorado) Escola de Comunicações e Artes, Universidade de São Paulo, São Paulo, 1990.

. Desenvolvimento de coleções. São Paulo: Polis: APB, 1989.

. Seleção de materiais de informação. 3. ed. Brasília, DF: Briquet de Lemos, 2010.

WOLTHERS, Clemência B. O escritório de advocacia e a informática jurídica. In: WOLTHERS,

Clemência B.; AZEVEDO, Danilo Soares de. A informática e o advogado. Brasília: Fundação Petrônio Portella, 1985. p. 13. 